\title{
AC 2012-4475: INCREASING THE RETENTION OF UNDER-REPRESENTED STUDENTS IN ENGINEERING THROUGH CONNECTIONS WITH AN INDUSTRY ADVISORY COMMITTEE
}

\section{Dr. Karen T. Marosi, Bucknell University}

Karen Marosi has been Associate Dean of Engineering at Bucknell University for 11 years. She has worked extensively in the area of student success in undergraduate engineering programs and has played a major role in the launching of the Engineering Success Alliance Program at Bucknell. Marosi holds a Ph.D. in civil engineering from the Pennsylvania State University and is a 2011 alumnus of the HERS Women in Higher Education Leadership Institute.

\section{Ms. Barbra Steinhurst, Bucknell University}

Barbra Steinhurst is the Director of the Engineering Success Alliance. She began her career as a statistician in Washington, D.C. Since then, she has taught mathematics at a variety of post-secondary institutions and has worked as a director in education-related non-profits. She earned an M.S. in mathematics from the University of North Carolina, Chapel Hill. 


\title{
Increasing the Retention of Under-Represented Students in Engineering Through Connections with An Industry Advisory Committee
}

\begin{abstract}
Meeting the increasing demands from industry for engineering graduates from diverse backgrounds poses a challenge for many universities. These challenges stem in part from a lack of recruitment of engineering majors from inner city and rural high schools and higher attrition rates for students from under-resourced high schools. Attrition rates are attributed to many factors including under-preparation for the mathematical and scientific rigor of an engineering curriculum and lack of academic capital from which to draw a general understanding of higher education and how to take full advantage of its offerings.
\end{abstract}

In an effort to increase retention and completion rates among under-represented students the Bucknell University College of Engineering has worked closely with Parsons Brinkerhoff Inc. to establish the Engineering Success Alliance (ESA). The ESA focuses on first-year engineering students from various inner-city recruiting programs and students from under-represented groups in engineering whose admissions materials suggest they might need extra support during the first two critical years in an engineering curriculum. Students are invited to participate in the ESA prior to their arrival on campus. Those who accept the invitation are then offered a variety of support activities targeted primarily at building mathematics skills, study skills, and academic capital. It is expected that these activities will assist in the retention of these students in engineering during the critical first two years of intense preparation for their engineering courses.

Integral to this process is an exceptionally active and motivated Advisory Committee made up of alumni from a variety of engineering disciplines and graduation years. These industry partners work not only to help raise funds to endow the program but also meet regularly with the students to mentor and inspire. The students and alumni share multiple meals a year together on campus and the students have been invited to visit partner offices and project sites. In exchange for the students' participation in the ESA activities, the industry partners will facilitate internship and professional development activities in the third and fourth years of the students' engineering program. When the students in the ESA program graduate, the Advisory Committee members will benefit from having built relationships with well-prepared engineering graduates with diverse perspectives and backgrounds. The true impact of the ESA has proven to be in the interactions between the industry partners and the students. Student motivation and persistence is immediately and noticeably different after each of these interactions. While the ESA is a young program that has not yet seen its first graduating class, preliminary assessments show that the presence of the Advisory Committee in this program has already proven integral to its success.

\section{Background}

The Engineering Success Alliance (ESA) is an academic success program that provides students from under-resourced high schools with the skills they need to be successful at Bucknell University in a nationally recognized engineering program. As observed by the CEO of Parsons Brinkerhoff Inc., also an alumnus of the College of Engineering, "The United States is simply 
not graduating enough engineers, and students from under-resourced areas, including minorities, are under-represented in the profession. To remain competitive as a company and as a country, we must draw students of all backgrounds into engineering fields.” These same thoughts are echoed in many recent publications including Rising Above the Gathering Storm ${ }^{1}$ and Rising Above the Gathering Storm, Revisited ${ }^{2}$ by the National Research Council. The College of Engineering has developed a partnership with this firm and several other industry partners to envision and implement a program that has the goal of serving as an innovative part of the national effort to increase diversity in the engineering workforce.

Bucknell University and the College of Engineering are dedicated to extending the advantages of the educational program to talented young men and women regardless of financial need.

Creating a more diverse student body is a high priority for the University. The class of 2015 for the University as a whole was $14.4 \%$ students of color which is defined as including those who identify as Black or African-American, Latino or Hispanic, Asian, Hawaiian or Pacific Islander, American Indian or Alaska native or two or more races. In the fall of 2009 the undergraduate population nationally at all four year universities was $30.7 \%$ students of color using the same definition $^{3}$. The University has a number of scholarship and tuition assistance programs in place to provide critical financial support to women in engineering, as well as first-generation students and students from diverse racial and ethnic backgrounds. The University recruits students from diverse communities through a number of special programs that identify and recruit talented students often from urban and inner city areas.

The College of Engineering is a highly selective and nationally recognized program. The acceptance rate for class of 2015 for the College of Engineering was 22\% and the average SAT score for the class of 2015 in Quantitative Reasoning was a 700. The University has experienced some challenges in meeting the needs of students entering the University from under-resourced high schools. Many of these high schools have not prepared their students thoroughly for the intense rigor of the curriculum in the fields of science, engineering and mathematics. While the students who are accepted into the College of Engineering possess the intellectual ability and character to succeed at the University, they can be underprepared in math and science and as a result struggle in their first-year courses. Students who are first generation college students often lack academic capital as well. They do not come to campus with the same knowledge base about navigating the college environment as students who have family members with college degrees ${ }^{4}$. The ESA program was developed in order to help promote the success of these students in the College of Engineering.

The ESA was implemented in 2010 and began by assisting 13 first-year members of the class of 2014. This cohort consisted of eight men and five women, seven of whom were Hispanic, four were Black, one was Asian and one was Caucasian. A second cohort of 15 first-year students from the class of 2015 was added in the fall of 2011. This cohort consisted of nine men and six women, seven of whom were Hispanic, three were Black, three were bi-racial and 2 were Asian. The program provides academic support, mentoring, networking and professional development opportunities to engineering students who may not have had access to a strong education in mathematics before enrolling at the University. The College of Engineering indentifies incoming students from targeted recruiting programs and from groups that are historically underrepresented in engineering whose math and science experience may not be consistent with that of 
traditional engineering students and invites them to be a part of the ESA program prior to arriving on campus. Indicators that are used to select participants are SAT scores, high school coursework, and underrepresented status in engineering. Students who accept the invitation participate in an ongoing program during the academic year that is focused on facilitating their transition to college and improving their fluency in the use of mathematics, communication skills, and study skills and is led by a professional math educator who also serves as director of the ESA program. The pedagogy of the program is designed to support its ideals as an academic success and empowerment program. The program is tailored to each student and his or her own academic progress. Some students work one-on-one with the ESA Director on specific math, study, or organizational skills. ESA provides peer tutor hours to students for whom this seems

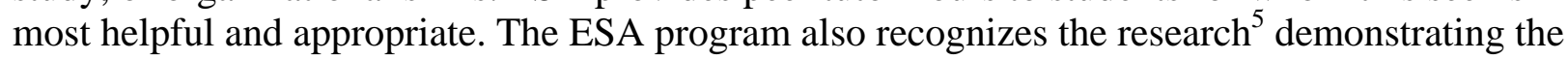
increased power of positive, community-related activities and instruction over more traditional tutoring and remediation methods. At its core, ESA is a community-building program, building relationships among the students as well as with alumni and other industry leaders. Early efforts to build academic community among the students have led to a critical program element called "Math Lab," inspired by the many emerging scholars programs ${ }^{6,7}$ built out of the work of Uri Treisman. Once or twice a week, students gather to work collaboratively on "challenge" problems in their respective calculus classes as well as non-curricular brain teasers and puzzlers. Through Math Lab, held outside of class time, ESA strives to instill a sense of confidence in problem-solving and in teamwork, as well as to support the classroom mathematics courses. A second key component of the ESA program is its industry Advisory Committee. The Advisory Committee serves to mentor the ESA students, assist in fund raising for the program, and to help provide professional development opportunities for the students as they progress through the engineering programs. The program will initially be funded by Parsons Brinkerhoff Inc. for the first five years and then supported by an endowment. The Advisory Committee and the University play key roles in soliciting support for the ESA endowment through their connections within the engineering industry.

\section{The ESA Industry Advisory Committee}

The ESA program has included the participation of an active, engaged and diverse industry Advisory Committee from the very beginning. Despite the fact that a significant portion of the initial funding for the ESA program has come from a single industry partner, the ESA program was deliberately not named for this partner in order to encourage industry partners from all engineering disciplines to contribute to and participate in the program. These Advisory Committee partners are integral in helping to raise funds to endow the program and helping to provide professional development experiences for the students such as internships after the students' second and third years in the engineering programs. They also meet regularly with the students to mentor and inspire them as they advance through the engineering major programs. Alumni and industry partners who are in a position to contribute strongly to the development of the ESA program are invited by the Dean of Engineering to join the Advisory Committee. Every attempt is made to ensure that the Advisory Committee contains industry partners from all of the engineering degree programs offered in the College of Engineering and that the membership also includes members from under-represented groups in engineering. The current Advisory

Committee consists of 13 members and includes the Dean of Engineering as a co-chair, the CEO of Parsons Brinkerhoff Inc. also as a co-chair, the president of the University, and 10 alumni 
with graduation years ranging from 1958-2004. Two of the Advisory Committee members come from racial groups that are under-represented in engineering, two Advisory Committee members are female, and at least two other Committee members were first-generation college students. Several of the Advisory Committee members serve in the roles of CEO, president or vice president of their respective companies.

Advisory Committee members interact with and mentor students during the academic year through sharing multiple meals together on campus and inviting the students to visit partner offices and project sites. Opportunities to interact with the Advisory Committee members also provide a strong motivator for the students to participate in the ESA program activities that revolve around academic success. Participation in the ESA program is voluntary on the part of the student but agreeing to participate requires that they attend and participate in many required components such as the Math Lab. The commitment of the Advisory Committee to the mentoring and professional development components allows for a way of rewarding students for their commitment. Students are also motivated to persist in engineering and the ESA programming by the Advisory Committee's visible commitment in their success. There is a reward for the Advisory Committee members as well when the students in the ESA program reach graduation. When the ESA students graduate the Advisory Committee members will benefit from having built relationships with well-prepared engineering graduates with diverse perspectives and backgrounds.

\section{Early Indicators of Success}

While the ESA is a young program that has not yet seen its first graduating class; preliminary assessments show that the programming related to the Advisory Committee is making an impact on the retention and performance of the students participating in the program.

The first cohort of students was asked to rank the ESA program elements at the conclusion of the 2010/2011 academic year. Ten program elements were listed and students were to rank the top five elements they found most useful. Seven out of 11 respondents listed meals with the Advisory Committee among their top five choices. The ESA students were offered an optional field trip to the headquarters and a major job site of a large civil engineering firm during the spring semester. Of the seven students who participated, five listed this experience among their top five useful elements. One went so far as to state that "The trip to [the headquarters and job site], although it was a single experience, was a life-changing experience because it was like opening the door to my future and taking a peek inside. I don't know how many students have experienced that privilege, but I was most appreciative about that.” Eight of 11 respondents indicated that knowing someone was watching out for their well being was among their top five most useful elements. Interaction between the Advisory Committee and the students appears to be a strong catalyst for student persistence and motivation. By observation it is apparent that student attitudes are immediately and noticeably different after each of these interactions. The survey responses also indicated that the opportunity to receive advice and hear the perspectives of alumni who have been successful engineers was valued by the students. This is an element worth noting because three of the Advisory Committee members provide role models of success by individuals from underrepresented groups in engineering. Given the lack of diversity on campus, access to these role models is proving to be a powerful program element. 
There has already been a noticeable difference in the academic performance between the first and second cohorts of students in the ESA program when comparing their academic standing at the end of their first semester. The average grade in the first calculus course of the students in the second cohort (class of 2015) was 0.8 GPA points higher than the first cohort (class of 2014). The Math Lab model and strong emphasis on community building was not used during the first semester of the ESA program. The cumulative fall semester GPA of the students in cohort two was 2.70 which was 0.15 GPA points higher than the first cohort in their first semester.

\section{Recommendations and Conclusions}

From our experiences related to the development of the ESA program and its industry Advisory Committee, we have found that attention to the composition of the Advisory Committee is crucial. Firstly, one natural role of the Advisory Committee is as fundraisers and vocal supporters of the program. A substantial number of the Committee members should be individuals who are in a position to support the program financially or have contacts among those who might be interested in supporting the program. Secondly, all attempts should be made to include members from underrepresented groups in engineering as part of the Advisory Committee. These members provide access to role models for students who may not normally be able to interact with successful engineering professionals. Finally, the Advisory Committee members play an integral role in student motivation and should have frequent opportunity to interact with students in the program. Advisory Committee members should ideally be personally invested in the program, with an openness and willingness to share their experiences as a way to inspire students to push through the academic difficulties, particularly those they face in their academic careers. These three characteristics of the Advisory Committee take the Engineering Success Alliance beyond a standard academic support program into a motivational and professional alliance that will ultimately bring together successful underrepresented professionals with the industries longing for them.

\section{References}

1) National Research Council, (2007), Rising Above the Gathering Storm: Energizing and Employing America for a Brighter Economic Future, Washington, DC: The National Academies Press.

2) National Research Council, (2010), Rising Above the Gathering Storm, Revisited: Rapidly Approaching Category

5, Washington, DC: The National Academies Press.

3) National Center for Education Statistics, (2010), Digest of Education Statistics 2010, Table 236, $333-334$.

4) Elam, C., Stratton, t., and Gibson, D.D., (2007), Welcoming a New Generation to College: The Millennial Students, Journal of College Admission, (195), 20-25.

5) Keimig, R.T. (1983), Raising academic standards: A guide to learning improvement, ASHE-ERIC Higher Education Report No. 4, Washington, DC: Association for the Study of Higher Education.

6) Conciatore, Jacqueline, (1990), From Flunking to Mastering Calculus: Treisman's Retention Model Proves to be

"Too Good" on Some Campuses, Black Issues in Higher Education 6(22), 5-6.

7) Alexander, B.B., Burda, A.C, and Miller, S.B. (1997), “A Community Approach to Learning Calculus: Fostering Success for Underrepresented Ethnic Minorities in an Emerging Scholars Program,” Journal of Women and Minorities in Science and Engineering 3(3), 145-159. 